\title{
Case study - Assessing Economic Potential for Demand Response in Baltic Balancing Market
}

\author{
Liga Sadovica, Gatis Junghans, Antans Sauhats, Zane Broka, Karlis Baltputnis, Valentins Lavrinovics \\ Institute of Power Engineering \\ Riga Technical University \\ Riga, Latvia \\ liga.sadovica@rtu.lv, gatis.junghans@gmail.com, sauhatas@eef.rtu.lv, zane.broka@rtu.lv, karlis.baltputnis@rtu.lv, \\ valentins.lavrinovics@ast.lv
}

\begin{abstract}
Demand response integration in balancing energy markets can provide significant financial savings for grid operators and market participants and promote optimal resource allocation. To facilitate demand response participation in power system balancing, the service must not only provide economic gains for the existing market participants, but it also has to present a viable business case for demand response service providers. Currently, in the Baltic states, there is no demand side participation in balancing markets. To support balancing market development, we analysed the economic potential of demand response for service providers. To forecast market conditions, we employed stochastic simulations for energy market prices and balancing product activation. Furthermore, to calculate the economic gains of a service provider, we used technical parameters of fridges obtained in a demand response pilot study and the demand response aggregation settlement model proposed by the Baltic TSOs and Finnish TSO. The preliminary results suggest sufficient financial incentives for future investments.
\end{abstract}

Keywords - aggregation, balancing market, demand response, economic analysis, $\mathrm{mFRR}$.

\section{INTRODUCTION}

The reliability of electric power system operation depends on the balance between power production and consumption [1]. To achieve this balance, every grid connection point needs to be accounted for [2]. Traditionally, this is managed by dividing the system in multiple imbalance areas each having a market participant, which is financially responsible for ensuring that all energy generated within the area is sold, and all energy consumed within the imbalance areas is bought. These market participants are called balance responsible parties (BRPs). BRPs ensure the balance by forecasting demand and supply of energy within their imbalance areas and ensuring according energy trades via day-ahead and intraday markets.

When BRPs fail to forecast demand and supply accurately, it can result in excess/ deficit energy in the power system. Forecasting errors are corrected in real time by transmission system operators (TSOs) via balancing market. Ensuring sufficient balancing energy reserves is pivotal to TSOs as without them the power system balance cannot be maintained, which, depending on the interconnections to other power systems, can result in costly procurement of balancing energy from other control areas or in adverse system frequency fluctuations.

This work has been supported by Latvian Council of Science, project: Management and Operation of an Intelligent Power System (I-POWER) (No. lzp-2018/1-0066).
The system balancing costs are covered by imbalance payments from those BRPs, whose actual consumption/ generation deviated from the forecast. Accordingly, the costlier balancing energy is, the more expensive penalty payments for forecasting errors are and consequently the costlier energy in retail markets becomes. The main driver for high balancing prices is balancing resource scarcity. Currently, in the Baltics, only electricity producers provide balancing resources. Furthermore, since the opening of the Common Baltic Balancing market and subsequent increased reliance on national balancing resources (instead of balancing energy resources from Russian TSO), we can observe preliminary indications of balancing resource scarcity [3].

Furthermore, according to the Baltic generation adequacy report, it is expected that during the next $10-15$ years the capacity required for balancing reserves will increase due to rising intermittent generation and the planned Baltic power system desynchronization from UPS/ISP. At the same time, the generation from some of the sources typically used for balancing purposes in the Baltic states (thermal power plants in Estonia) will reduce by up to $50 \%$ due to lost competitiveness of oil-shale power plants caused by the increasing costs of $\mathrm{SO}_{2}$ and $\mathrm{NO}_{2}$ emissions [3]. The forecasted generation mix for the Baltic states is presented in Fig. 1.

This gives us clear indications that additional sources for balancing reserves are needed. Demand response (DR) is a promising source of balancing energy to consider. DR integration in balancing energy markets can provide significant financial savings for grid operators and market participants and promote optimal resource allocation [4]. Some large consumers in the Baltic states have already expressed preliminary interest in providing services to the TSOs [5]. However, to facilitate DR participation in power system balancing, the service must provide economic gains for both the existing market participants and DR service providers. The main contribution of this paper lies in estimations of the financial potential of DR for a service provider in the context of the Common Baltic balancing market and DR settlement model proposed by Baltic TSOs [6].

The rest of the paper is organized as follows. Section II presents an overview of the relevant market framework. Data used for simulations and the model setup is explained in Section III. Section IV summarizes the results and, finally, the conclusions are drawn in Section VI. 


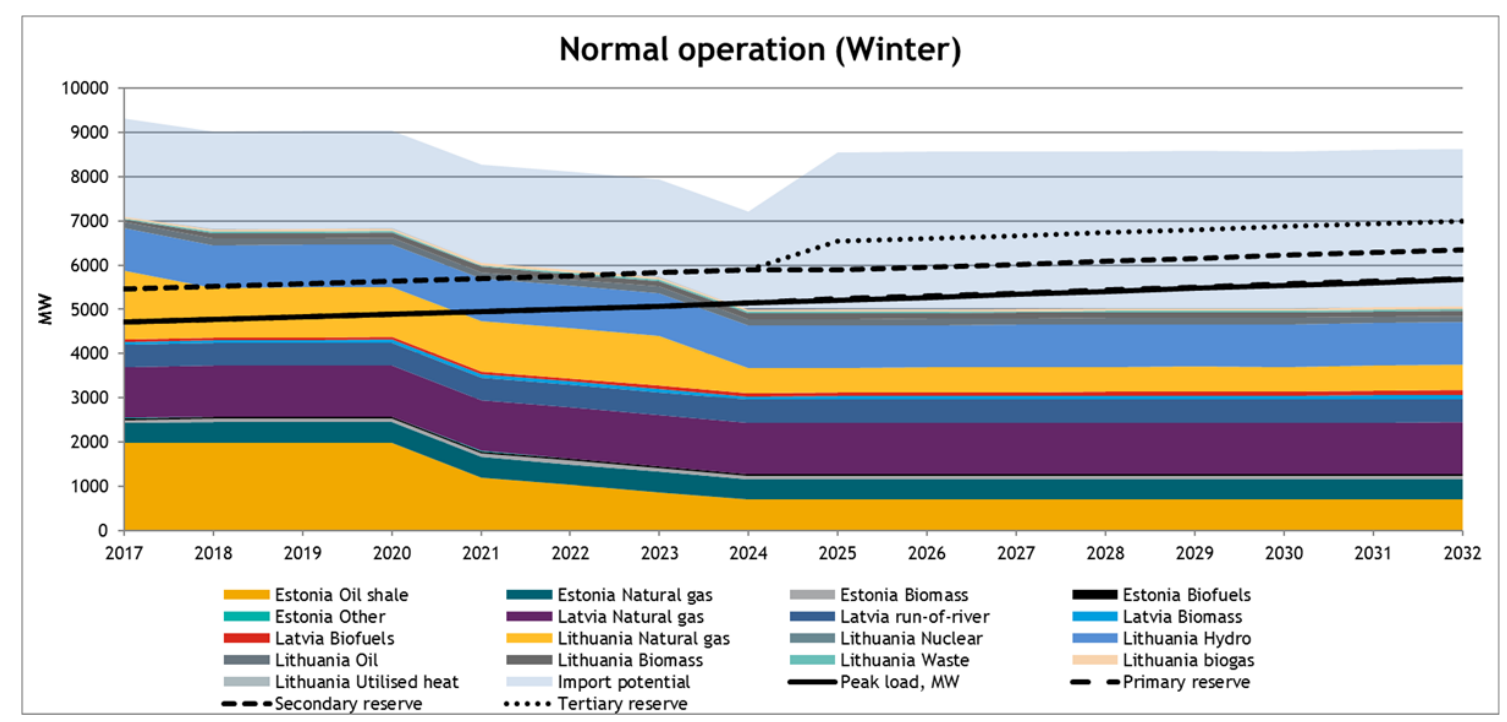

Fig. 1. Forecasted available electricity supply capacity in the Baltic region in winter [2]

\section{INDEPENDENT DR AGGREGATION IN BALANCING MARKET}

DR service is a temporal change in consumer's energy consumption due to a reaction to price signals or other measures [7]. DR is associated with multiple benefits, such as increased system flexibility, improved network congestion management, cost-effective deferral of grid investments and improved energy efficiency [8], [9]. DR can be broadly divided in two groups: implicit and explicit DR. Implicit (price-based) DR refers to consumers choosing to be exposed to timevarying electricity prices and/ or time-varying network tariffs that reflect the real cost of electricity at the time of use and allow the consumer to react to prices depending on their preferences. On the other hand, explicit DR refers to a program, where demand competes directly with supply in the wholesale, balancing and ancillary services markets directly or through the services of aggregators. This is achieved through controlled changes in the load that are traded in the electricity markets, providing a resource comparable to generation, and receiving a commensurate compensation [9], [10]. Based on the mFRR product specification, only explicit DR is applicable when considering balancing market [2].

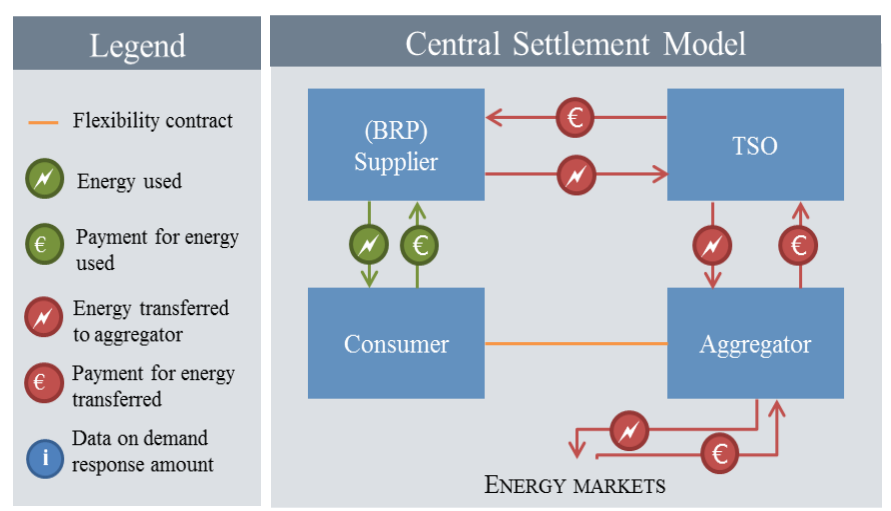

Fig. 2. Central settlement model
Large industrial plants in Europe (e.g. in the Nordics, Poland, Croatia, the Netherlands, Germany) have been involved in DR provision for ancillary services for considerable time [9], [10]. These large consumers can participate in the market individually. In the Baltics, the energy intensive industry is not highly developed, accordingly the DR potential is locked in smaller consumers (i.e. SMB, residential). A rough estimate suggests that both for residential and commercial buildings (such as schools, hotels, retailers) approximately $50 \%$ of energy consumption stems from heating, cooling, ventilation and lighting [11]. This indicates substantial flexibility potential, however, given that the minimum bid size for mFRR product is $1 \mathrm{MW}$, these consumers can only participate in the balancing market, if their loads are aggregated and coordinated. Advancements in information technology renders such aggregation and resource coordination feasible.

While it is an energy related product, DR aggregation requires different business processes in place compared to a typical energy supplier. To ensure that all consumers willing to participate in DR are allowed to, without switching their supplier, a new market participant - an independent aggregator - emerged. In essence, an independent aggregator is a DR aggregation service provider that delivers balancing energy sourced from end-users that are included in imbalance areas different to the aggregator [6]. There is no consensus on the best market framework for the integration of independent DR aggregators, since effect models differ by countries and types of electricity markets [9], [10]. The settlement model currently favored by the Baltic TSOs is a Centralized model (Fig. 2) [6].

\section{CHARACTERIZATION OF THE SIMULATION SET-UP}

\section{A. Assumptions for Energy Transfer}

When DR activation takes place, it has the following impact on the consumption curve (Fig. 3). When DR activation for upwards regulation (i.e. reduced consumption) takes place, the consumption is curtailed. 


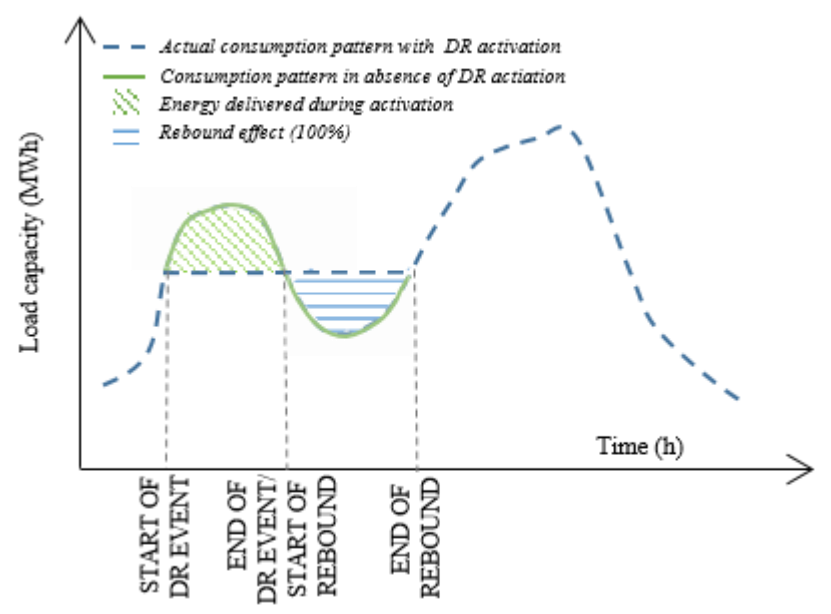

Fig. 3. DR activation explained

Depending on the resource type, the energy unconsumed during the activation will be consumed to some extent during one or few following hours. Based on the results of the pilot with fridges [1], the assumed recovery effect in our simulations is $100 \%$ and it takes place during the next hour. Within our simulation framework, it is assumed that the volumes of energy transferred can be determined without an error.

\section{B. Assumptions for the Settlement Model (Cash-Flows)}

Within the simulation, it is assumed that the following prices are equal:

- Retail price is equal to the day-ahead price.

- Balancing price is equal to the imbalance price.

In line with the Centralized settlement model, the following trades for the energy delivered during activation take place:

1) Before an operational hour, Supplier/ BRP buys energy in day ahead market at day-ahead price $\left(\mathrm{P}_{\mathrm{DA}}\right)$.

2) During the operational hour, TSO orders balancing energy from aggregator at balancing price $\left(\mathrm{P}_{\mathrm{bal}}\right)$.

3) During the operational hour, consumer does not consume the energy it would consume in the absence of TSO's activation order.

4) During a settlement phase, TSO makes an imbalance adjustment for the declared position of the impacted BRP.

5) During the settlement phase, TSO pays BRP compensation for the energy taken from its portfolio at reference price $\left(\mathrm{P}_{\mathrm{ref}}\right)$.

6) During the settlement phase, TSO pays Aggregator the difference between $\mathrm{P}_{\text {bal }}$ and $\mathrm{P}_{\text {ref. }}$.

7) During the settlement phase consumer does not pay for the energy unconsumed and may receive part of the profit generated by the difference between $\mathrm{P}_{\text {bal }}$ and $\mathrm{P}_{\text {ref. }}$.

The following trades for the consumption pattern deviation caused by the recovery effect take place:

1) During the settlement phase, consumer pays BRP/ Supplier retail price $\left(\mathrm{P}_{\text {ret }}\right)$ of the recovery hour for the energy consumed due to the recovery effect.
2) During the settlement phase, the BRP pays imbalance price $\left(\mathrm{P}_{\mathrm{bal}}\right)$ of the recovery hour to the TSO for the energy consumed due to the recovery effect.

\section{The Simulation Tool}

The modelling for the case study is carried out using a Monte-Carlo simulations-based tool introduced and elaborated in [12]. The stochastic nature of the model requires the output to be probabilistic instead of deterministic. Consequently, most of the input settings concern the expected mean of a particular parameter across scenarios and the output is provided in the form of probability distributions.

The main modules of the tool are day-ahead price scenario generation, balancing liquidity and price scenario generation, balancing activation simulation, short-term and long-term economic assessment.

\section{Input Assumptions and DR Resource Characterization}

The assumptions for day-ahead market were made based on the historical values from Nord Pool day-ahead market data for the Baltics in 2017. The assumptions are presented in Table I.

The assumptions for the balancing market were made based on the historical values for the Baltic balancing market data for the first quarter of 2018. These reference values were chosen due to the significant market changes implemented on January 1, 2018. The assumptions are presented in Table II.

We based technical assumptions about the DR resource on the data presented in a pilot study by Lakshmanan et. al (2016) [1]. We set the total load capacity at $2.5 \mathrm{MW}$ (25 fridges). The load profile for a typical day is depicted in Fig. 4.

DR activation parameters are presented in the Table III. Minimum DR bid price is set at $45 € / M W h$ to limit events where DR activation causes losses due to price difference between day-ahead price and balancing price. Based on the historical data from 2017, day-ahead price in Baltic region was below $45 € / \mathrm{MWh} 85 \%$ of times.

We assume that the resource participates only in upwards regulation. Furthermore, it is assumed that participation in DR does not damage the resource and consequently does not add other additional costs.

TABLE I. DAY-AHEAD MARKET DATA SIMULATION PARAMETERS

\begin{tabular}{|l|l|}
\hline \multicolumn{1}{|c|}{ Price simulation parameters } & \multicolumn{1}{c|}{ Value (st. dev.) } \\
\hline Mean price for 99.5\% of hours & $34.02 € / \mathrm{MWh}(10 \%)$ \\
\hline $\begin{array}{l}\text { Mean value for weekdays divided by mean } \\
\text { value for weekends }\end{array}$ & $1.23(10 \%)$ \\
\hline $\begin{array}{l}\text { Mean value for day (06:00-22:00) divided by } \\
\text { mean value of night (22:00-06:00) }\end{array}$ & $1.38(10 \%)$ \\
\hline Minimum price & $2.99 € / \mathrm{MWh}(10 \%)$ \\
\hline Maximum price for 99.5\% of hours & $75.34 € / \mathrm{MWh}(10 \%)$ \\
\hline Maximum price for $100 \%$ of hours & $130.05 € / \mathrm{MWh}(10 \%)$ \\
\hline Number of scenarios & 300 \\
\hline
\end{tabular}

TABLE II. BALANCING MARKET DATA SIMULATION PARAMETERS

\begin{tabular}{|l|l|}
\hline \multicolumn{1}{|c|}{ Price simulation parameters } & \multicolumn{1}{|c|}{ Value } \\
\hline$\%$ of hours when regulation takes place & $70 \%$ \\
\hline $\begin{array}{l}\% \text { of regulation hours, where upwards regulation is } \\
\text { required (load reduction) }\end{array}$ & $45 \%$ \\
\hline Balancing price for upwards regulation (expectation) & $1.6 \mathrm{P}_{\mathrm{DA}}$ \\
\hline Balancing price for downwards regulation (expectation) & $0.6 \mathrm{P}_{\mathrm{DA}}$ \\
\hline Number of scenarios & 300 \\
\hline
\end{tabular}




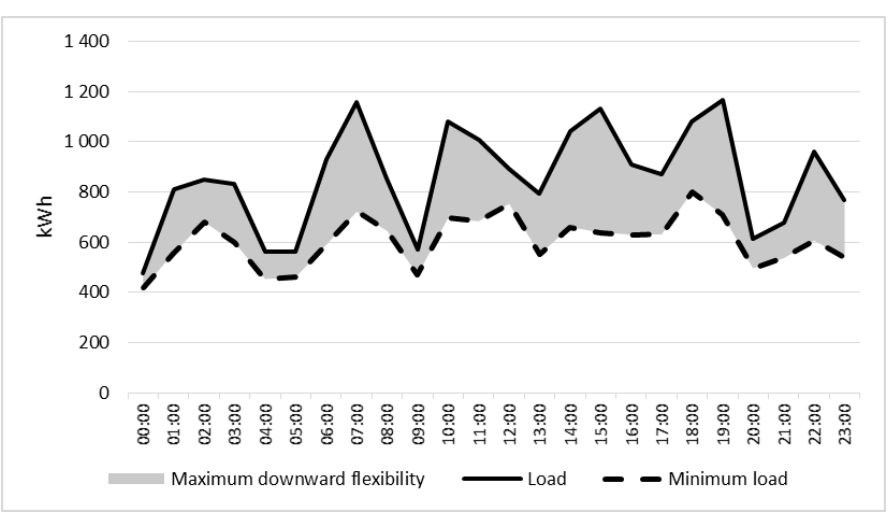

Fig. 4. Load profile of the DR resource simulated

TABLE III. DR RESOURCE SIMULATION PARAMETERS

\begin{tabular}{|l|l|}
\hline \multicolumn{1}{|c|}{ DR resource simulation parameter } & \multicolumn{1}{c|}{ Value } \\
\hline Maximum number of events during 24 hours & 6 \\
\hline Minimum time between the events & $2 \mathrm{~h}$ \\
\hline Maximum period before rebound & $2 \mathrm{~h}$ \\
\hline Rebound effect / DR energy delivery & $100 \%$ \\
\hline Minimum DR bid price & $45 € / \mathrm{MWh}$ \\
\hline Discount rate used for NPV calculations & $3 \%$ \\
\hline
\end{tabular}

\section{REsUlts}

The portfolio's expected average annual income from participation in balancing market is $8622.89 € .85 \%$ of that is the revenue from balancing market payments and $15 \%$ stems from day-ahead price difference between the activation hour and recovery hour (Fig. 5). There is no benefit from energy savings in this case study, since we assumed that all the curtailed consumption would be recovered later.

Assuming a 10-year asset service life and 3\% discount rate, the expected net present value (NPV) of the simulation described in the previous section is $73555.01 €$. In other words, the project would be profitable, if the initial investment was below $73555.01 €$ or below $2942.20 €$ per fridge (Fig. 6).

It is expected that on average the portfolio will annually deliver 326.24 MWh of balancing energy, by participating in $32 \%$ of all hours (1257 hours annually) when downwards regulation is used. Accordingly, on average, the portfolio earns $26.43 €$ per each MWh delivered to the balancing market (Fig. 7).

The expected average annual cash inflow for the portfolio is equal to $19661.18 €$, while the expected average cash outflow for the portfolio is $11038.29 €$ (Fig. 8).

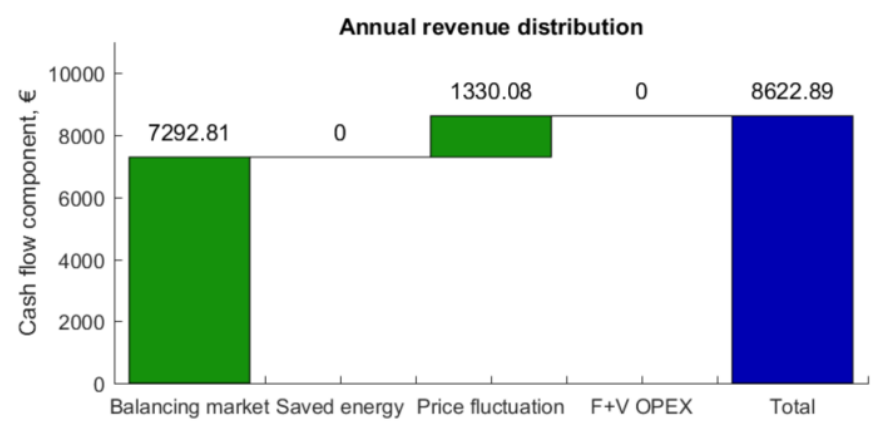

Fig. 5. Average annual revenue distribution

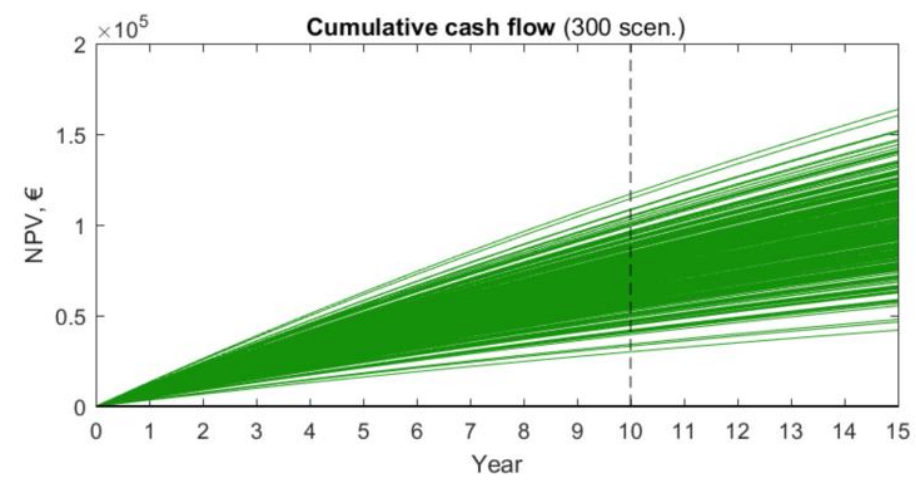

Fig. 6. Cumulative cash-flow for 15 years (all scenarios)

\section{CONCLUSIONS}

DR is associated with multiple benefits, such as increased system flexibility, improved network congestion managment, cost-effective deferral of grid investments and improved energy efficiency. However, to ensure that these benefits can be achieved, market needs a non-discriminatory framework that not only protects all the market participants from undue burdens but also facilitates business opportunities for DR aggregators. The preliminary assessment of expected economic gains from the small DR resource aggregation within the Baltic Balancing market employing Central Settlement model for aggregator integration seems promising. It suggests that there is existing balancing reserve potential in the Baltics.

For further research, we suggest reviewing more DR resource types, and, if possible, comparison of modelled expected benefits and the actual gains should be piloted to further verify the accuracy of the simulations. Furthermore, the simulation tool could be used to determine the optimal reference (compensation) price by assessing financial impacts not only on the aggregator but also on BRPs.
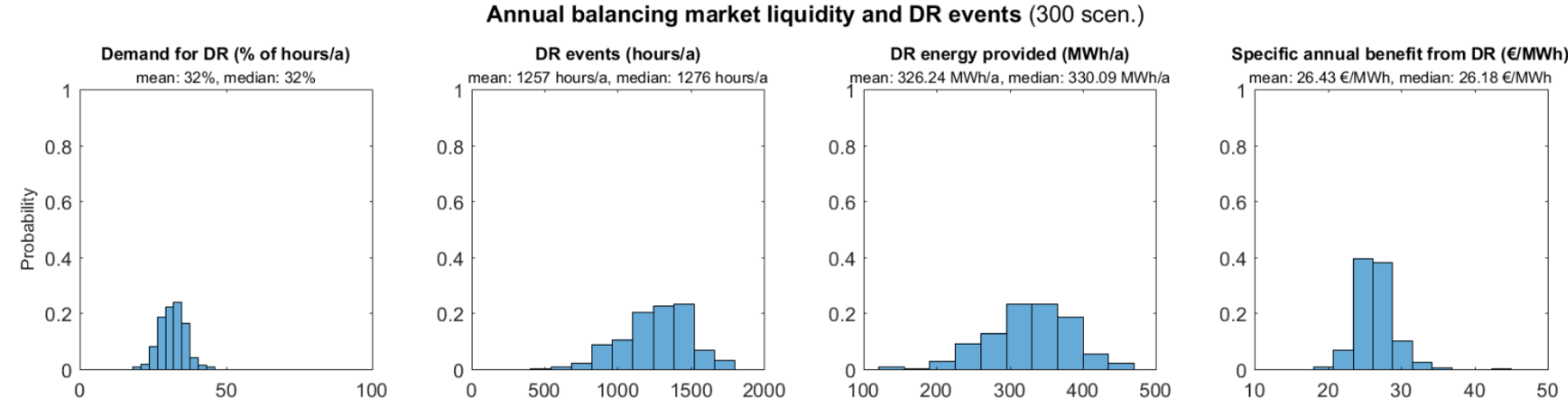

Fig. 7. Overview of simulated DR events and balancing market prices 

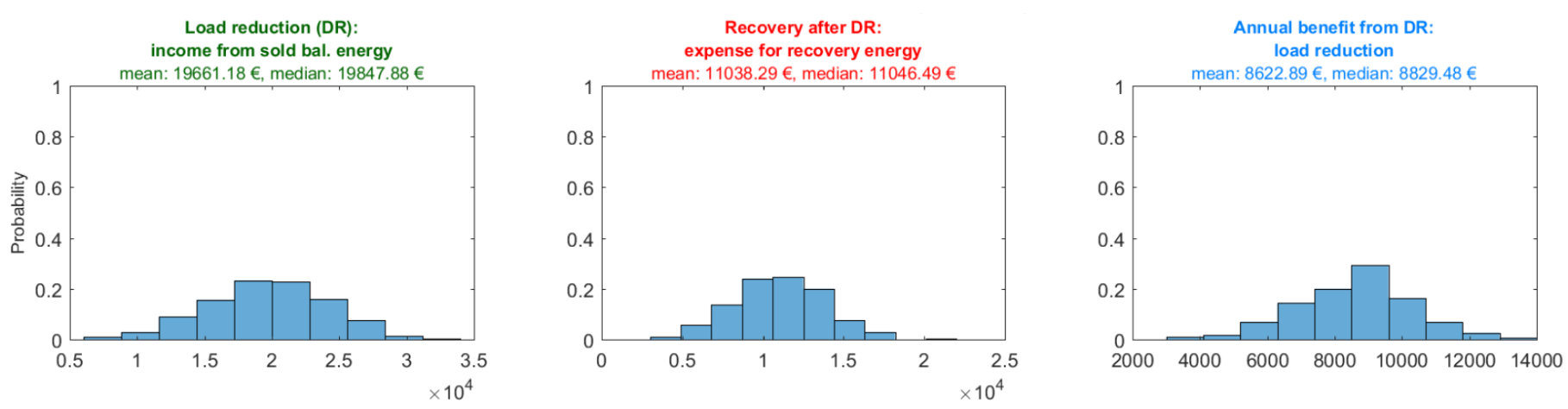

Fig. 8. Breakdown of DR owner's annual profit

\section{REFERENCES}

[1] V. Lakshmanan, M. Marinelli, J. Hu, and H. W. Bindner, "Experimental Analysis of Flexibility Change with Different Levels of Power Reduction by Demand Response Activation on Thermostatically Controlled Loads," Electr. Power Components Syst., vol. 45, no. 1, pp. 88-98, Jan. 2017.

[2] A. "Augstsprieguma Tīkls", "Pārvades sistēmas operatora ikgadējais novērtējuma ziṇojums," $2016 . \quad$ [Online]. Available: http://www.ast.lv/sites/default/files/editor/PSO_Zinojums_2016.pdf. [Accessed: 21-May-2018].

[3] AS "Augstsprieguma tīkls," Elering AS, and Litgrid UAB, "Demand Response Through Aggregation - a Harmonized Approach in Baltic Region," 2017. [Online]. Available: https://elering.ee/sites/default/files/public/Elektriturg/Demand Response through Aggregation a Harmonized Approach in the Baltic....pdf. [Accessed: 15-Jan-2018].

[4] S. Mishra, H. Koduvere, I. Palu, R. Kuhi-Thalfeldt, and A. Rosin, "Assessing demand side flexibility with renewable energy resources," in 2016 IEEE 16th International Conference on Environment and Electrical Engineering (EEEIC), 2016, pp. 1-6.

[5] I. Drovtar, P. Uuemaa, A. Rosin, J. Kilter, and J. Valtin, "Using demand side management in energy-intensive industries for providing balancing power - The Estonian case study," in 2013 IEEE Power \& Energy Society General Meeting, 2013, pp. 1-5.

[6] Chua-Liang $\mathrm{Su}$ and D. Kirschen, "Quantifying the Effect of Demand Response on Electricity Markets," IEEE Trans. Power Syst., vol. 24, no. 3, pp. 1199-1207, Aug. 2009.
[7] C. Eid, P. Codani, Y. Perez, J. Reneses, and R. Hakvoort, "Managing electric flexibility from Distributed Energy Resources: A review of incentives for market design," Renew. Sustain. Energy Rev., vol. 64, pp. 237-247, Oct. 2016.

[8] K. Li, B. Wang, Z. Wang, F. Wang, Z. Mi, and Z. Zhen, "A Baseline Load Estimation Approach for Residential Customer based on Load Pattern Clustering," Energy Procedia, vol. 142, pp. 2042 2049, Dec. 2017

[9] SEDC, "Mapping Demand Response in Europe Today," 2017. [Online]. Available: http://www.smartenergydemand.eu/wpcontent/uploads/2017/04/SEDC-Explicit-Demand-Response-inEurope-Mapping-the-Markets-2017.pdf. [Accessed: 10-May-2017].

[10] U.S. Energy Information Administration, "COMMERCIAL BUILDINGS ENERGY CONSUMPTION SURVEY (CBECS)," 2013. [Online]. Available: https://www.eia.gov/consumption/commercial/data/2012/\#b22-b33. [Accessed: 24-May-2018].

[11] E. and M. The National Academies of Sciences, "Heating \& Cooling." [Online]. Available: http://needtoknow.nas.edu/energy/energy-efficiency/heatingcooling. [Accessed: 21-May-2018].

[12] Z. Broka, K. Baltputnis, A. Sauhats, L. Sadovica, and G. Junghans, "Stochastic Model for Profitability Evaluation of Demand Response by Electric Thermal Storage," in 2018 IEEE 59th International Scientific Conference on Power and Electrical Engineering of Riga Technical University (RTUCON), 2018, pp. 1-6.

This is a post-print of a paper published in Proceedings of the 2018 IEEE 59th International Scientific Conference on Power and Electrical Engineering of Riga Technical University (RTUCON 2018) https://doi.org/10.1109/RTUCON.2018.8659901 and is subject to IEEE copyright. ISBN 978-1-5386-6904-4. e-ISBN 978-1-5386-6903-7. 